\title{
Assessment of the Physicochemical Properties and In Vitro Dissolution of Glibenclamide Tablets Marketed in Saudi Arabia
}

\author{
Gamal A. Shazly ${ }^{1,2, *}$ and Gamal M. Mahrous ${ }^{1}$ \\ ${ }^{1}$ Department of Pharmaceutics, King Saud University, PO Box 2457, Riyadh 11451, Saudi Arabia \\ ${ }^{2}$ Department of Industrial Pharmacy, Faculty of Pharmacy, Assiut University 71526, Assiut, Egypt
}

\begin{abstract}
Glibenclamide (GBD), also known as glyburide, is an oral hypoglycemic of the sulfonylurea group that is frequently prescribed for the treatment of noninsulin dependent diabetes mellitus. The aim of this study was to assess the pharmaceutical quality of new formulations and four generic marketed glibenclamide tablets in Saudi Arabia in comparison with the innovator product (Daonil tablets). Friability, uniformity of dosage unit, disintegration, and in vitro drug release for the investigated products were determined. The friability was less than $1 \%$ for all products. The innovator and the tested products all passed the content uniformity test according to USP 34. The acceptance values ranged from 3.8 to 6.4. The disintegration time of all products in distilled water, ranging from 3 to $14 \mathrm{~min}$, met USP requirements. In vitro release testing of innovator, new formulations, and generics was carried out in phosphate buffer $\mathrm{pH} 7.4$ and pH 7.8, and in borate buffer $\mathrm{pH}$ 9.5. The similarity in dissolution profiles $\left(f_{2}\right)$ was assessed using the FDA recommended approach. The $f_{2}$ factor increases with increasing $\mathrm{pH}$ from 7.4 to 9.5; $\mathrm{pH} 9.5$ is optimum for correlation for some generics (Brands II, III, and IV), while pH 7.8 is optimum for Brand I. Formula IV exhibited a dissolution profile similar to that of the innovator and had the highest $f_{2}$ similarity factor at $\mathrm{pH}$ 7.4.
\end{abstract}

KEYWORDS: Glibenclamide; dissolution; similarity factor; formulations.

\section{INTRODUCTION}

$\longrightarrow$ rug absorption is affected by the release of the drug from the dosage form, dissolution of the drug from dissolution media resembling physiological media, and the permeability of the drug through the gastrointestinal tract. Therefore, the in vivo performance of a drug can be assessed by in vitro dissolution.

Dissolution is considered one of the most important quality control tests performed on pharmaceutical dosage forms and is now developing into a tool for predicting bioavailability.

In drugs with low aqueous solubility and high permeability, a relationship between in vitro dissolution rate of many drugs and their bioavailability has been demonstrated (1).

For FDA approval, generic drugs have to contain the same active ingredients, be identical in strength, and be bioequivalent to the innovator product (2). Compared with the innovator product, the structure of the active pharmaceutical ingredient in a generic formulation is exactly the same, but it can be formulated in different ways (3).

In a multinational, postmarket comparative study, the dissolution behavior of different glibenclamide formulations was correlated to oral performance and bioavailability of such products (4).

Glibenclamide (Glb), an oral hypoglycemic agent belonging to the sulfonylurea class, is used for the treatment of noninsulin dependent diabetes (Figure 1). It has a his-

${ }^{*}$ Corresponding author. tory of low bioavailability, which is attributed to its poor dissolution properties. As a weak acid with a $\mathrm{p} K_{\mathrm{a}}$ of 5.3 , its solubility strongly depends on the $\mathrm{pH}$ of the test medium and particle size (5). Its hypoglycemic effect is mainly due to stimulation of insulin release from pancreatic beta cells and sensitization of the peripheral tissues to insulin (6). Glb controls sugar levels by stimulating insulin secretion in the pancreas and increases tissue sensitivity to insulin (7).

Because of its low aqueous solubility and high permeability, Glb is therefore a Class II drug based on the Biopharmaceutics Classification System (BCS). Bioavailability is not used to classify the drug under BCS (8). Glibenclamide is currently marketed in Saudi Arabia by a number of pharmaceutical companies.

The aim of the present study was to evaluate four marketed Glb tablets ( $5 \mathrm{mg}$ ) in Saudi Arabia and compare new Glb tablet formulations with the innovator product according to the United States Pharmacopeia and Food and Drug Administration guidelines.

\section{MATERIALS AND METHODS \\ Materials}

Glibenclamide micronized powder was a gift from SPIMACO (Saudi Arabia). Sodium phosphate dibasic, dicalcium phosphate (DicaPh), monopotassium phosphate, and magnesium stearate were purchased from Riedel de Haën (Seelze, Germany). Sodium hydroxide, boric acid, and phosphoric acid were supplied by BDH Laboratory Supplies (England). Microcrystalline cellulose (MCC, 


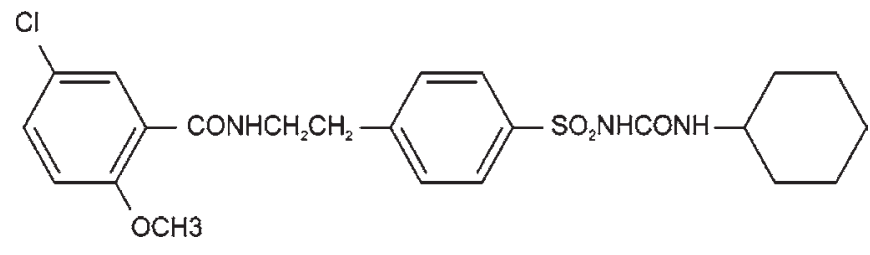

Figure 1. Chemical structure of glibenclamide.

Avicel PH101) was purchased from Serva Feinbiochemica (Heidelberg, Germany). Acetonitril was purchased from Merck (Germany). The innovator product (Daonil 5-mg tablets) and the four generic products-Euglucon, Glidiabet, Glibil, and Diatab (each containing $5 \mathrm{mg} \mathrm{Glb}$ )—were purchased from the local market of Saudi Arabia.

\section{Methods}

Preparation of Glb New Formulation Tablets by Direct Compression Method

The corresponding amounts of Glb, dicalcium phosphate (DCP), and Avicel PH 101 (Table 1) were accurately weighed and mixed using a Turbula mixer (Erweka, S2Y, Heusenstamm, Germany) for ten minutes. The specified amount of sodium laurate was then mixed with the powder in the turbula mixer for an additional one minute. The powder was compressed into tablets weighing $200 \mathrm{mg}$ using a Korsh single-punch machine with a 9-mm shallow concave punch (Erweka, EKO, Germany).

\section{Differential Scanning Calorimetry (DSC)}

The powdered samples (3-5 mg) were hermetically sealed in aluminum pans and heated from 25 to $200^{\circ} \mathrm{C}$ at a constant rate of $10^{\circ} \mathrm{C} / \mathrm{min}$ (DSC-60, Shimadzu, Japan). Data were processed using a TA 50I PC system with Shimadzu software programs. An indium standard was used to calibrate the DSC temperature and enthalpy scale, and nitrogen was used as a purging gas at a rate of $40 \mathrm{~mL} / \mathrm{min}$.

\section{Tablet Friability}

Friability of tablets was carried out using Roche friabilator. Friability was evaluated from the percentage weight

Table 1. Composition of Glb Tablet Formulations

\begin{tabular}{ccccc}
\hline Formula No. & \multicolumn{4}{c}{ Ingredients (\% w/w) } \\
\cline { 2 - 5 } & Glb & MCC & $\begin{array}{c}\text { Dicalcium } \\
\text { Phosphate }\end{array}$ & Mg Stearate \\
\hline I & 5 & 193 & - & 2 \\
\hline II & 5 & 168 & 25 & 2 \\
\hline III & 5 & 143 & 50 & 2 \\
\hline IV & 5 & 118 & 75 & 2 \\
\hline V & 5 & 93 & 100 & 2 \\
\hline
\end{tabular}

Tablet weight: $200 \mathrm{mg}$ loss of 20 tablets tumbled in a friabilator at $25 \mathrm{rpm}$ for 4 $\mathrm{min}$. The tablets were dedusted, and the loss in weight caused by fracture was recorded as the percentage weight loss. Friability less than $1 \%$ was considered acceptable.

$$
\% \text { Friability }=100\left(1-\frac{W_{1}}{W_{2}}\right)
$$

where $W_{1}$ is the total weight of six tablets before friability and $W_{2}$ is the total weight of six tablets after friability.

\section{HPLC Analysis}

The amount of Glb was analyzed using a previously validated method (9). The HPLC system was composed of a Waters HPLC system (Milford, MA, USA) equipped with a dual absorbance detector, a binary HPLC pump, and a reversed-phase $C 18$ column $(4.6 \times 150 \mathrm{~mm}$, Hypersil, Asheville, NC, USA). The HPLC system was monitored by Empower (Waters) software. The mobile phase was a mixture of acetonitrile/water (40:60) filtered through 0.45-mm membrane filter and eluted at a flow rate of $1 \mathrm{~mL} / \mathrm{min}$; the injection volume was $20 \mu \mathrm{L}$, and the retention time was $2.8 \pm 0.2 \mathrm{~min}$. The effluent was monitored at $225 \mathrm{~nm}$.

\section{Uniformity of Dosage Units}

The uniformity of dosage units can be demonstrated by either content uniformity or weight variation according to USP 34 (10). Content uniformity is based on the assay of the drug substance in a number of individual dosage units to determine whether the individual contents are within set limits. Ten tablets were taken, and each tablet was assayed individually as stated in the monograph. Individual tablets were placed in 50-mL volumetric flasks, $1 \mathrm{~mL}$ of water was added to each, and the flasks were shaken till disintegration of the tablets occurred. Ethanol $(10 \mathrm{~mL})$ was added, and the flasks were shaken mechanically for $30 \mathrm{~min}$. Each flask was then brought to volume with ethanol. An aliquot was centrifuged at about $3000 \mathrm{rpm}$, and $20 \mu \mathrm{L}$ of the clear supernatant was injected to the chromatograph.

\section{Dissolution Studies}

In vitro drug release was performed for the tablets according to the USP $34<711>$ Dissolution procedure for immediate-release dosage forms. Six tablets from each new formula and twelve tablets for the brands were tested. The dissolution of $\mathrm{Glb}$ from tablets was monitored using an automated dissolution tester (LOGAN Instrument Corp, Somerset, NJ, USA) coupled to an automated sample collector (SP-100 peristaltic pump, Somerset, NJ, USA). The USP Apparatus 2 paddle was used at $50 \mathrm{rpm}$. The media used were phosphate buffer $\mathrm{pH}$ 7.4, phosphate buffer $\mathrm{pH}$ 7.8 , and borate buffer $\mathrm{pH} 9.5$ (all prepared according USP) maintained at $37 \pm 0.5^{\circ} \mathrm{C}$. The amount of Glb released from each tablet in the dissolution samples was determined by the HPLC method mentioned above. Dissolution 
profiles for the prepared formulas and for each product were compared with the innovator to determine the efficacy of the generic products and new formulations. The dissolution medium at $\mathrm{pH} 9.5$ was selected in accordance with the USP monograph of Glb. The two other $\mathrm{pH}$ values (7.4 and 7.8) were selected to mimic the physiological pH of the GIT.

\section{Data Analysis}

Analytical data were analyzed using Excel software programs for statistical and graphical comparisons. To compare the dissolution profiles of all generic and innovator brands, the model-independent approach of similarity factor $\left(f_{2}\right)$ was employed. The similarity factor $\left(f_{2}\right)$ is a logarithmic reciprocal square root transformation of the sum-of-squared error and is a measurement of the similarity in percent dissolution between the two curves calculated as (11)

$$
f_{2}=50 \cdot \log \left\{\left[1+\frac{1}{n} \sum_{t=1}^{n}\left(R_{t}-T_{t}\right)^{2}\right]^{-0.5} \times 100\right\}
$$

where $n$ is the sampling number, $R_{t}$ and $T_{t}$ are the percent dissolved of the reference and test products, respectively, at each time point $t$. The percent error is zero when the test and drug reference profiles are identical and increases proportionally with the dissimilarity between the two dissolution profiles.

WHO has set a public standard of the $f_{2}$ value between 50 and 100 to indicate similarity between two dissolution profiles (12).

\section{RESULTS AND DISCUSSION}

Differential scanning calorimetry (DSC) offers information about melting, crystallization, decomposition, or a change in heat capacity and is useful to assess the physicochemical status of the entrapped drug as well as the interaction among different compounds. As shown in Figure 2, the thermogram of pure Glb is typical of a crystalline anhydrous substance showing a sharp endothermic peak at $174^{\circ} \mathrm{C}$ corresponding to its melting point. The DSC thermogram of the physical mixture was approximately the superposition of the raw material DSCs where the individual components are clearly distinguishable. This indicates there is no interaction between Glb and the excipient used.

\section{Tablet Friability}

The results of friability tests of the new formulas and Glb tablets brands are depicted in Table 2. All brands of Glb tablets showed friability values less than $1 \%$.

\section{Uniformity of Dosage Units}

The content uniformity of Glb tablets was performed, and the acceptance value was calculated according to USP 34 (10). The acceptance values for all new formulas

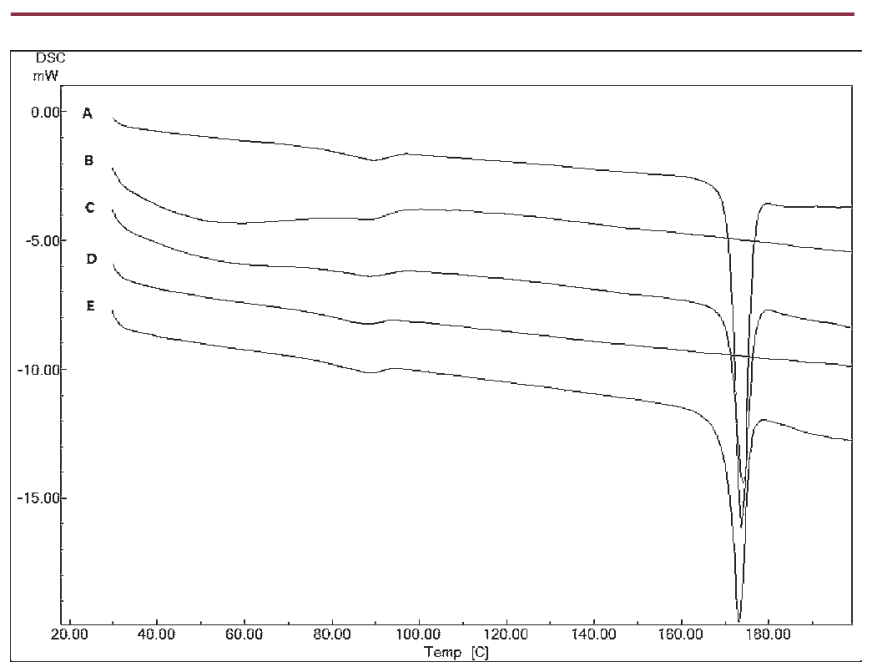

Figure 2. DSC thermogram of (A) Glb, (B) Avicel 101, (C) Glb/Avicel 101 (physical mix 1:1), (D) DCP, and (E) Glb/DCP (physical mixture 1:1).

Table 2. Percent Friability of New Formulas and Glb Tablet Brands

\begin{tabular}{cc}
\hline Product/New Formulation & \% Friability \\
\hline Innovator & 0.11 \\
\hline Brand I & 0.3 \\
\hline Brand II & 0.14 \\
\hline Brand III & 0.38 \\
\hline Brand IV & 0.18 \\
\hline Formula I & 0.73 \\
\hline Formula II & 0.57 \\
\hline Formula III & 0.73 \\
\hline Formula IV & 0.57 \\
\hline Formula V & 0.48 \\
\hline
\end{tabular}

Table 3. Content Uniformity of Glb Tablets

\begin{tabular}{cc}
\hline Product/New Formulation & Acceptance Value \\
\hline Innovator & 5.7 \\
\hline Brand I & 3.8 \\
\hline Brand II & 5.52 \\
\hline Brand III & 5.67 \\
\hline Brand IV & 4.87 \\
\hline Formula I & 6.4 \\
\hline Formula II & 5.8 \\
\hline Formula III & 6.2 \\
\hline Formula IV & 6.1 \\
\hline
\end{tabular}


and Glb tablets were less than 15 (the maximum allowed acceptance value, $L_{1}$ ) as shown in Table 3 .

\section{In Vitro Release Studies}

The dissolution test is a measure of the amount of the drug released into the dissolution medium over time. Dissolution tests are a standard method used to ensure the batch-to-batch conformity of oral dosage forms. Today most pharmacopeias describe four different dissolution test apparatus: basket, paddle, reciprocating cylinder, and flow-through cell. The most often recommended methods are the basket and the paddle because of their precise and simple setup and handling (5).

Figures 3-5 show dissolution profiles of the generic and the innovator products at $\mathrm{pH} 7.4,7.8$, and 9.5. The results of Glb dissolved from the innovator and generics after one hour were $58 \%, 63 \%, 70 \%, 36 \%$, and $67 \%$ at pH 7.4. At pH 7.8, the results of Glb dissolved from the innovator and generics after one hour were $73 \%, 68 \%, 100 \%, 60 \%$, and $83 \%$, while

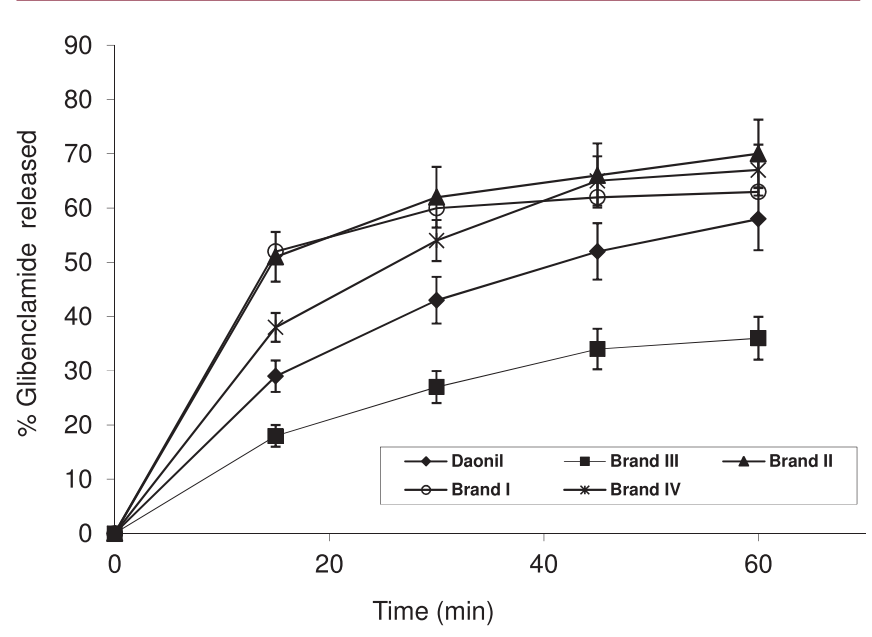

Figure 3. Dissolution profiles of Glb reference standard and four brands in phosphate buffer at $\mathrm{pH} 7.4$.

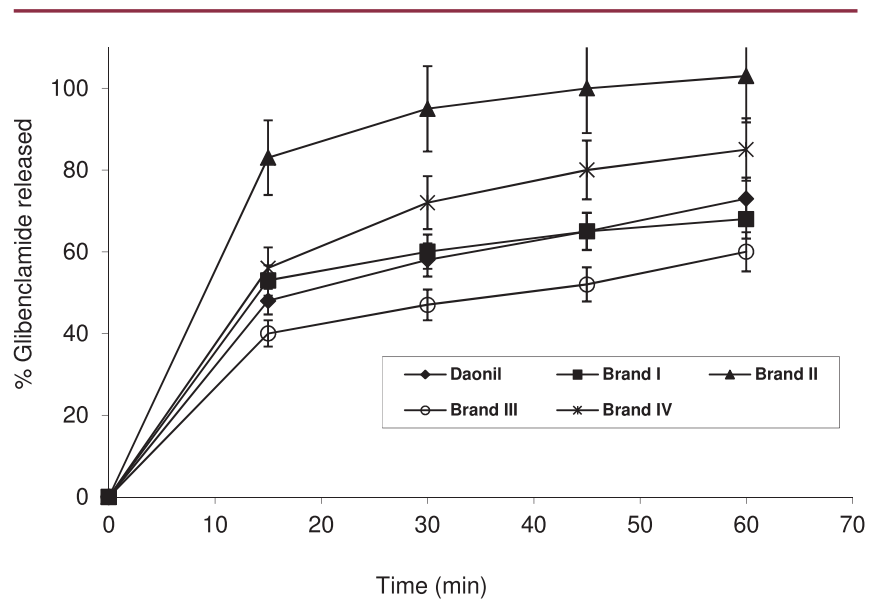

Figure 4. Dissolution profiles of Glb reference standard and four brands in phosphate buffer at $\mathrm{pH} 7.8$. at $\mathrm{pH}$ 9.5, the results of Glb dissolved from the innovator and generics after one hour were $99 \%, 68 \%, 100 \%, 93 \%$, and $98 \%$. These results show that there are differences among dissolution profiles of the generic and innovator products. These differences are reflected by $f_{2}$ ratios as shown in Table 4. These findings are in agreement with those in a previous study by Blume et al. (13) of 142 glibenclamide tablet formulations from 28 countries from Europe, Africa, North and South America, Asia, and Australia. They recorded marked differences among product in vitro dissolution behavior.

The $f_{2}$ factor increases with increasing $\mathrm{pH}$ from 7.4 to 9.5 . This might be due to the fact that Glb is a weak acid with a $\mathrm{p} K_{\mathrm{a}}$ of 5.3 and its solubility strongly depends on the $\mathrm{pH}$ of the test medium. It seems that a pH of 9.5 is optimum for a correlation in similarity with the tested generics (Brands II, III, and IV). The exception was with Brand I, which shows a higher $f_{2}$ ratio at $\mathrm{pH} 7.8$ and could be due to formulation factor.

Figure 6 and Table 5 show dissolution profiles and $f_{2}$ values of the new formulas and the innovator at $\mathrm{pH} 7.4$. These results show that a correlation can be developed at this $\mathrm{pH}$, and that more than one dissolution time point is needed to characterize release from the dosage form completely. This is consistent with the FDA guideline for IR products, which states that for slowly dissolving or poorly water-soluble drugs (BCS Case 2), a two-point dissolution specification, one at $15 \mathrm{~min}$ to include a dissolution range (dissolution window) and the other at a later point (30,

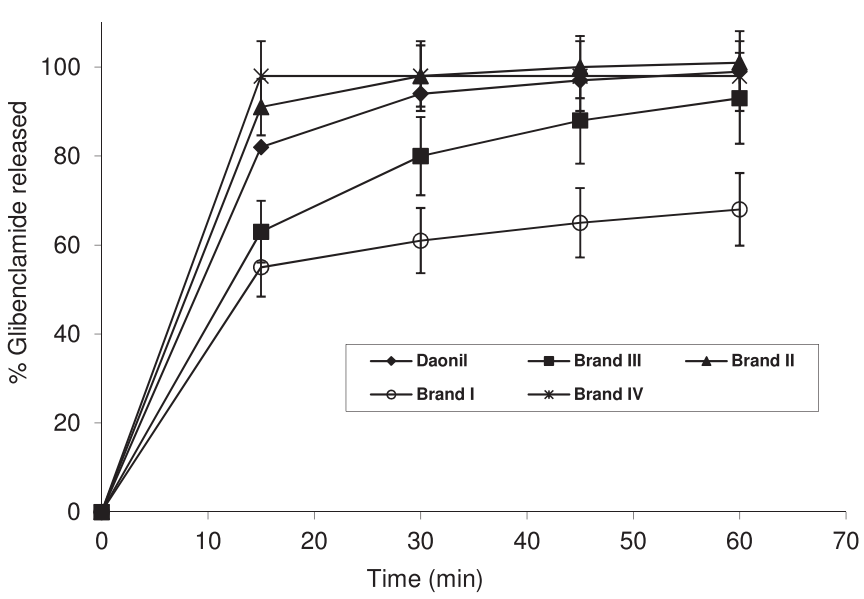

Figure 5. Dissolution profiles of Glb reference standard and four brands in phosphate buffer at $\mathrm{pH} 9.5$.

Table 4. $f_{2}$ Values of the Four Brands at Different $\mathrm{pH}$ Values

\begin{tabular}{lccc}
\hline \multirow{2}{*}{ Product } & \multicolumn{3}{c}{$\boldsymbol{f}_{\mathbf{2}}$ value } \\
\cline { 2 - 4 } & $\mathrm{pH} \mathrm{7.4}$ & $\mathrm{pH} \mathrm{7.8}$ & $\mathrm{pH} \mathrm{9.5}$ \\
\hline Brand I & 37.82 & 74.3 & 25.58 \\
\hline Brand II & 36.46 & 22.37 & 60.99 \\
\hline Brand III & 40.74 & 48.11 & 50 \\
\hline Brand IV & 47.61 & 44.72 & 50.91 \\
\hline
\end{tabular}




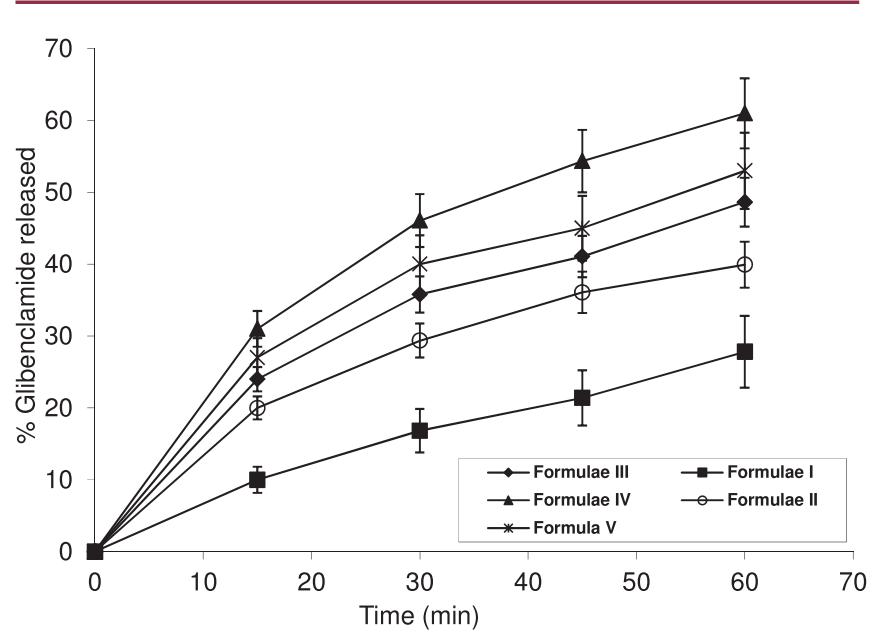

Figure 6. Dissolution profiles of Glb Formulas I-V in phosphate buffer at pH 7.4.

Table 5. $f_{2}$ Values of New Formulations Compared with the Innovator at $\mathrm{pH} 7.4$

\begin{tabular}{lc}
\hline Product & $\boldsymbol{f}_{\mathbf{2}}$ value at $\mathbf{p H ~ 7 . 4}$ \\
\hline Formula I & 36 \\
\hline Formula II & 57 \\
\hline Formula III & 75.5 \\
\hline Formula IV & 83 \\
\hline Formula V & 59 \\
\hline
\end{tabular}

$45,60 \mathrm{~min}$ ) to ensure $80 \%$ dissolution, is recommended to characterize the quality of the product (5). In a previous report (14), the effect of magnesium hydroxide on the absorption and efficacy of two Glb preparations was investigated in healthy volunteers in two separate studies, using a randomized cross-over design with two phases. Concomitant ingestion of magnesium hydroxide and nonmicronized Glb may greatly enhance the absorption and efficacy of Glb. The absorption of micronized Glb appears to be only slightly influenced by magnesium hydroxide. These findings could explain the enhancement effect of the presence of calcium phosphate dibasic on GLB release from formulas II, III, and IV, which contain 25, 50, and 75 $\mathrm{mg}$ calcium phosphate dibasic, respectively, compared with the formula that does not contain calcium phosphate dibasic. This could be attributed to the increase in the microenviromental $\mathrm{pH}$ within the stagnant layer during dissolution process, which resulted in an increase in dissolution rate of the weak acid GLB. However, increasing the amount of calcium phosphate dibasic to $100 \mathrm{mg}$ resulted in a decrease in dissolution rate compared with formula IV. This could be attributed to a delay in disintegration time as seen in Table 3. Figure 7 shows that the new formula IV seems to have a dissolution profile similar to that of the innovator ( $f_{2}$ similarity factor of 83$)$.

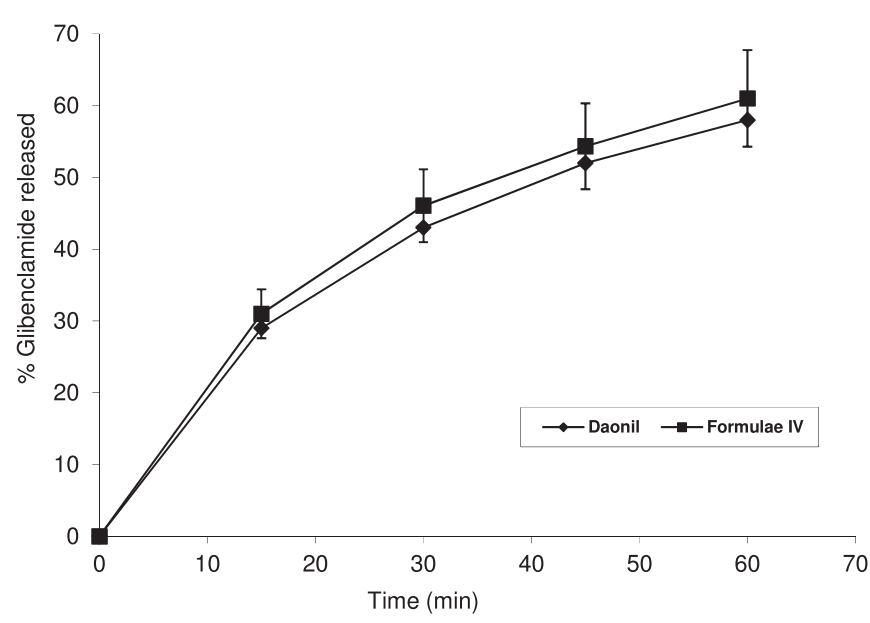

Figure 7. Dissolution profiles of Glb reference standard and Formula IV in phosphate buffer at $\mathrm{pH} 7.4$.

\section{CONCLUSIONS}

Different dissolution patterns were observed for the different brands of glibenclamide tablets that were evaluated. However, increasing the $\mathrm{pH}$ of the dissolution medium from 7.4 to 9.5 decreased the differences in the dissolution behavior. New formulations prepared by direct compression showed good physicochemical properties. Formula IV exhibited a dissolution profile similar to that of the innovator and had the highest $f_{2}$ similarity factor at $\mathrm{pH} 7.4$, which mimics the physiological $\mathrm{pH}$ of the GIT.

\section{ACKNOWLEDGMENT}

The authors would like to extend their sincere appreciation to the Deanship of Scientfic Research at King Saud University for its funding of the work through the research group project no. RGP-VPP-139.

\section{REFERENCES}

1. Enami, J. In vitro-In vivo Correlation: From Theory to Applications. J. Pharm. Pharm. Sci. 2006, 9 (2), 31-51.

2. Meyer, G. F. History and Regulatory Issues of Generic Drugs. Transplant. Proc. 1999, 31 (3), 10S-12S.

DOI: 10.1016/S0041-1345(99)00105-0.

3. Dissolution Testing of Immediate Release Solid Oral Dosage Forms; Guidance for Industry; U.S. Department of Health and Human Services, Food and Drug Administration, Center for Drug Evaluation and Research (CDER), U.S. Government Printing Office: Washington, DC, 1997. http://www.fda.gov/downloads/ drugs/guidancecomplianceregulatoryinformation/ guidances/ucm070237.pdf (accessed Oct 20, 2014).

4. Blume, H.; Ali, S. L.; Siewert, M. Pharmaceutical Quality of Glibenclamide Products: A Multinational Postmarket Comparative Study. Drug Dev. Ind. Pharm. 1993, 19 (20), 2713-2741. DOI: 10.3109/03639049309050174. 
5. Löbenberg, R.; Kramer, J.; Shah, V. P.; Amidon, G. L.; Dressman, J. B. Dissolution Testing as a Prognostic Tool for Oral Drug Absorption: Dissolution Behavior of Glibenclamide. Pharm. Res. 2000, 17(4), 439-444. DOI: 10.1023/A:1007529020774.

6. Sweetman, S. C., Ed. Martindale, the Complete Drug Reference, 33rd ed.; Pharmaceutical Press: London, 2002.

7. Hardman, J. G., Limbird, L. E., Molinoff, P. B., Ruddon, R. W., Gilman, A. G., Eds. Goodman \& Gilman's The Pharmacological Basis of Therapeutics, 9th ed.; McGrawHill: New York, 1996; pp 1487-1518.

8. Löbenberg, R.; Amidon, G. L. Modern bioavailability, bioequivalence and biopharmaceutics classification system. New scientific approaches to international regulatory standards. Eur. J. Pharm. Biopharm. 2000, 50 (1), 3-12. DOI: 10.1016/S09396411(00)00091-6.

9. Panchal, H. A.; Tiwari, A. K. Formulation Development and In-Vitro Evaluation of Bilayer Tablets of Glibenclamide as Immediate Release and Metformin $\mathrm{HCl}$ as Sustained Release. Int. J. Pharm. Sci. Health Care 2012, 4 (2), 1-18.
10. The United States Pharmacopeia and National Formulary USP 34-NF 29; The United States Pharmacopeial Convention, Inc.: Rockville, MD, 2011.

11. Sayar, E.; Şahin, S.; Cevheroğlu, S.; Hincal, A. A. Comparison of dissolution profiles of two commercially available cotrimoxazole tablets. FABAD J. Pharm. Sci. 2008, 33, 87-94.

12. WHO Expert Committee on Specifications for Pharmaceutical Preparations. Proposal to waive in vivo bioequivalence requirements for WHO Model List of Essential Medicines immediate-release, solid oral dosage forms; WHO Technical Report Series, No. 937, Annex 8; World Health Organization: Geneva, Switzerland, 2006.

13. Blume, ; Ali, S. L.; Siewert, M. Pharmaceutical Quality of Glibenclamide Products A Multinational Postmarket Comparative Study. Drug Dev. Ind. Pharm. 1993, 19 (20), 2713-2741. DOI: 10.3109/03639049309050174.

14. Neuvonen, P.; Kivistö, K. The effect of magnesium hydroxide on the absorption and efficacy of two glibenclamide preparations. Br. J. Clin. Pharmacol. 1991, 32 (2), 215-220. DOI: 10.1111/j.1365-2125.1991. tb03884.x. 